\title{
BMJ Open Assessing access to paediatric trauma centres in Canada, and the impact of the golden hour on length of stay at the hospital: an observational study
}

\author{
Ofer Amram, ${ }^{1}$ Nadine Schuurman, ${ }^{1}$ Ian Pike, ${ }^{2,3}$ Michael Friger, ${ }^{4}$ Natalie L Yanchar ${ }^{5}$
}

To cite: Amram 0 Schuurman N, Pike I, et al. Assessing access to paediatric trauma centres in Canada, and the impact of the golden hour on length of stay at the hospital: an observational study. BMJ Open 2016;6:e010274. doi:10.1136/bmjopen-2015010274

- Prepublication history and additional material is available. To view please visit the journal (http://dx.doi.org/ 10.1136/bmjopen-2015010274).

Received 19 0ctober 2015 Revised 30 November 2015 Accepted 15 December 2015

CrossMark

For numbered affiliations see end of article.

Correspondence to Dr Ofer Amram; oamram@sfu.ca

\section{ABSTRACT}

Objectives: In Canada injuries are a leading cause of death and morbidity among the paediatric population. Trauma systems have been established across North America to provide comprehensive injury care and to lead injury control efforts. However, not all populations have equal access to trauma care services. This is an observational study with the aim of assessing the impact of geographical access to paediatric trauma centres (PTCs) on patient outcomes, and to determine spatial access to PTCs across Canada.

Setting: To examine the relationship between access to PTC and injury outcome, length of stay at the PTC was determined for all injured patients who live within and outside of 60 min driving time of the PTC. To determine spatial access to PTCs across Canada, a list of level 1 and 2 PTCs was identified across Canada. A $1 \mathrm{~h}$ driving time catchment was created around each PTC in order to estimate spatial accessibility.

Participants: Hospital administration data sets from British Columbia (BC) and the Nova Scotia (NS) trauma registry were used to assess the impact of spatial access on paediatric injury (ages $0-15$ years) outcomes. The data sets provided case-level data including the Injury Severity Score, postal code of place of residence, age and length of hospital stay. Results: In NS and BC, average length of stay at the hospital is significantly lower inside 60 min driving time compared to outside of 60 min driving time from a PTC ( $p<0.05$, using a non-parametric $t$ test). In Canada, approximately $65 \%$ of the paediatric population resides within $1 \mathrm{~h}$ of a PTC.

Conclusions: This paper highlights differences in injury outcomes as a result of access. However, further investigation is needed as other considerations such as type of injury, age and/or gender may also affect injury outcomes.

\section{BACKGROUND AND OBJECTIVES}

Within Canadian paediatric populations, injuries are the leading cause of death and morbidity, with an annual monetary cost of \$C5.1 billion. ${ }^{1}$ Worldwide, there are more

\section{Strengths and limitations of this study}

- The first study to assess the impact of geographical access to paediatric trauma centres (PTCs) on patient outcomes.

- The study determines spatial access to PTCs across Canada for the paediatric population.

- Length of stay at the hospital is not a patient focus outcome.

- Place of residence was used as a proxy for place of injury.

deaths from injury in the first four decades of a person's life than from any other cause. ${ }^{2}$ By way of response, trauma systems have been established across North America to provide comprehensive injury care and to lead injury control efforts. Unfortunately, however, not all populations have equal access to trauma care services.

Paediatric trauma centres (PTCs) were developed in response to a recognition that children have unique characteristics, and that injured children may require specialised care. ${ }^{3}$ In 1999, the American College of Surgeons' Committee On Trauma declared that care for injured children "may be optimally provided in the environment of a children's hospital with a demonstrated commitment to trauma care." ${ }^{4}$ Other research suggests that children with severe injuries should be sent to a PTC or, at minimum, be treated within a trauma centre where a paediatric surgeon is present. ${ }^{4}$ In the USA, the number of PTCs grew from 37 in 1997 to 65 in 2009. However, they are still very scarce when compared with adult trauma centres (ATC). In fact, in 2009, only $10 \%$ of children were treated in PTCs, up from 3\% in 1997. ${ }^{34}$ It has been shown that the care provided to injured children by PTCs is superior to that of ATCs. ${ }^{5-7}$

In Canada, PTCs are defined as paediatric tertiary care facilities "with facility with a full 
array of medical specialties and ready access to advanced medical technology...Medical staff and hospital resources are dedicated and/or prioritized to the care of the major pediatric trauma patient ensuring rapid access to required care in a preplanned system of care." The advantages of PTCs include the provision of specialised paediatric services in addition to access to paediatric trauma research, education and prevention strategies. In order to estimate the availability of trauma resources among the population, trauma studies typically use the widely accepted 'golden hour' concept (which states that survival rates improve when care is given within the first hour). ${ }^{2}$ Using the $1 \mathrm{~h}$ driving time parameter, a US study estimated that close to $84 \%$ of US residents have access to trauma centres providing definitive care. ${ }^{9}$ A similar study in Canada, found that $77.5 \%$ of Canadians live within a $1 \mathrm{~h}$ drive of a trauma centre. ${ }^{2}$ This type of research can be focused to measure the accessibility of specific subpopulations (eg, children) in terms of access to specialised facilities such as PTCs. Such information will allow an estimation of the proportion of the population with poor accessibility to specialised trauma care, and will enable the introduction of prevention strategies intended to reduce injury rates in those locations.

The objective of this study is to examine the impact of geographical access to PTCs on patient outcomes in a Canadian setting, and to determine spatial access to PTCs across Canada. For the purpose of this study, length of stay at the hospital will be used as a proxy for injury outcome.

\section{METHODS}

\section{Settings and participants}

Hospital administration data sets from the British Columbia (BC) and the Nova Scotia (NS) trauma registries were used to assess the impact of spatial access on paediatric injury (age $0-15$ years) outcomes. ${ }^{10}{ }^{11}$ These two Canadian provinces are situated at the two extreme latitudes of Canada, and have relatively mature inclusive trauma systems, each has a single level I PTC which serves as the hub of the provincial paediatric trauma system. ${ }^{12} 13$ Each provincial data set provided case-level data including the Injury Severity Score (ISS) (calculated using International Classification of Diseases 10 codes), the patient's place of residence at the six-digit postal code level, gender, age, treatment hospital and length of hospital stay (used as a proxy measure of injury outcome). All patients with an ISS of 12 and over were included in the data as such injuries are severe enough to warrant admission to hospital. It also included details as to whether the patient was directly or indirectly (seen at another hospital first and then transferred) admitted to the PTC, and the geographic location of the PTCs, ATCs and non-trauma hospitals for each province. The primary reason for using these two provinces for this analysis is due to data availability (with locations at the postal code level). However, we believe these two provinces differ enough, geographically, to provide a good insight on how spatial access may impact length of stay (LOS) at the hospital.

To determine spatial access to PTCs across Canada, we first identified a list of level 1 and 2 PTCs across the country through direct communication with provincial representatives of the Trauma Association of Canada. ${ }^{14}$ Population counts for each dissemination area (DA) were obtained from the 2006 Canadian census conducted by Statistics Canada. ${ }^{15}$ Population variables were taken from the census at the DA level. Each DA is typically composed of neighbouring streets that host somewhere between 400 and 700 residents. Because of differences in the population density across different communities, DA-level data is highly accurate in urban areas, but is less accurate in more rural settings.

\section{Driving time calculation and population estimation}

All location data (including patient's place of residence and location of PTCs across Canada) was geo-coded using DMTI GeoPinPoint. ${ }^{16}$ For the injury data sets, driving time between the patient's place of residence and the hospital was calculated using the network analyst function in ArcGIS. The driving time variable for each injury incident was then added to the data set.

Also using the ArcGIS network analyst, a $1 \mathrm{~h}$ driving time catchment was created around each PTC in order to estimate accessibility. Estimations of the population count (for patients aged 0-19 years) both inside and outside of the $1 \mathrm{~h}$ driving time catchment were established by joining the population-weighted centroid of each DA within $2500 \mathrm{~m}$ of a road segment. Network Analyst allows for relatively accurate estimations of travel time as it provides turn-by-turn calculations while taking into account road speed limits. A more detailed explanation of this methodology can be found in previous publications. ${ }^{17} 18$ The DMTI road data set was used to supply the road network data. This data provides uniform coverage across Canada, and is suitable for use with Network Analyst.

\section{Analysis}

In order to examine whether a relationship existed between access to PTC and injury outcome, all injured patients treated at a PTC were selected. The mean and median length of stay at the PTC was then determined for all injured patients who live within and outside of 60 min driving time of the PTC. Separate but identical analyses were conducted; one for NS and the other for BC.

\section{Spatial clustering}

In order to visualise the relationship between spatial access to trauma centres and length of stay at the hospital, all injuries were mapped in BC and NS. Using local Geits G spatial clustering of statistically significant 
locations of injuries $(\mathrm{p}<0.05)$ with elevated length of stay of at the hospital were identified.

\section{RESULTS}

\section{Spatial access and length of stay at the hospital}

Nova Scotia

There were 347 moderate to severe (ISS $>12$ ) injuries in NS between the years 2001 and 2010. Eighty-five per cent of those injuries were treated at the IWK Health Centre, the only designated PTC in the province (see online supplementary table S1); the rest were treated in other hospitals across the province, none of which are strictly paediatric. Of the injuries treated at IWK, almost $100 \%$ of those within a 60 min drive of the hospital were directly admitted; of those more than 60 min away, $84 \%$ were directly admitted. For those within $60 \mathrm{~min}$ of IWK, the median length of stay was 4 days, while for those outside of $60 \mathrm{~min}$, this value increased to 7 days (figure 1). A non-parametric independent samples $\mathrm{t}$ test was conducted to compare length of stay at the hospital within $60 \mathrm{~min}$ and outside $60 \mathrm{~min}$, and a significant difference was found $(p=0.001)$. Gaps in length of stay clearly increase as the severity of the injury increased (table 1).

\section{British Columbia}

There were 1710 moderate to severe (ISS >12) paediatric injuries in BC between the years 2001 and 2010. Almost $40 \%$ (682) of those injuries were treated at BC Children's Hospital, while the remainder were treated at other non-PTCs across the province. For injuries treated at BC Children's Hospital, $47 \%$ of the injuries inside $60 \mathrm{~min}$ were directly admitted to the hospital, while outside of $60 \mathrm{~min}$, this dropped to $18 \%$. The median length of stay at the PTC was 3 days for patients within 60 min driving time, and 5 days for those outside this 60 min catchment (figure 2). Like NS, the length of stay did change as the injuries become more severe (table 2), and the nonparametric independent samples t test was also significant $(\mathrm{p}=0.02)$.

\section{Access to PTCs in Canada}

There are 14 level 1 or 2 PTCs in Canada. With the exception of Prince Edward Island (PEI) and New Brunswick, all Canadian provinces have at least one PTC. Ontario has four dedicated PTCs, while BC, Newfoundland, Manitoba, Saskatchewan and NS each have one.

According to the 2006 census, there are approximately 7692835 children between the ages of 0 and 19 years in Canada. Approximately $65 \%$ of this population resides within $1 \mathrm{~h}$ of a PTC. The province of Ontario, where just over $75 \%$ of the children reside within $1 \mathrm{~h}$ of a PTC, has the highest PTC accessibility within Canada (figure 3). New Brunswick, PEI and the territories do not have PTCs and, as a result, have very low accessibility levels, with almost the entire population more than an hour away.

\section{DISCUSSION}

This paper highlights the importance of timely access to PTCs by demonstrating the relationship between PTC proximity and injury outcomes (defined as length of stay at the hospital). Using the concept of the 'golden hour', the paper also assesses spatial access of Canadian paediatric populations to PTCs. Several studies have highlighted the importance of PTCs in caring for injured children. For example, a study by Densmore et al, ${ }^{7}$ which analysed approximately 80000 cases of paediatric trauma from 27 states in the USA, found that children who were treated in PTCs had significantly lower mortality rates than those treated in ATCs or in ATCs with a children's unit. In addition, the author found the length of hospital stay to be much higher in ATCs and ATCs with children's units. The author concluded that severely injured children were much better off being treated in a PTC. ${ }^{7}$ Similar results were obtained in the analysis of 13351 patients treated at accredited trauma centres in the state of Pennsylvania. ${ }^{10}$ This study found that children who were treated at a PTC or an ATC with a demonstrated commitment to care of children had a much better chance of survival than those treated at trauma centres without any paediatric-specific expertise, especially those with an ISS of $>15$. The use of more appropriate procedures (operative vs non-operative) may be one of the important factors resulting in better outcomes of paediatric trauma patients in PTCs. ${ }^{11-13}$ Use of more appropriate treatment is related to better survival rates, better outcomes and even cost savings, in terms of length of hospital stay. ${ }^{5}{ }^{19}$ Traumatic brain injury is the most common cause of mortality among paediatric trauma patients, causing approximately $75 \%$ of the injury-related deaths. When treated at a PTC or an ATC with paediatric-specific expertise, these patients have been found to have significantly lower mortality and higher functional outcome rates than those treated at an ATC. ${ }^{12} 20$

Timely access to trauma care is a critical component of better health outcomes for children. This has been shown in a number of studies where both morbidity and mortality were higher in rural areas with restricted access to PTCs. ${ }^{5} 1921$ The results from our study also showed a clear distinction in injury outcomes for those at greater distances from the PTC at which they were treated (more vs less than $1 \mathrm{~h}$ ). This is not surprising, as trauma centres are better equipped to deal with moderate to severely injured patients. Such centres typically have surgeons on call on a continuous basis as well as trauma teams trained to deal with severe injuries. ${ }^{22}$ However, in a country such as Canada, it is difficult to provide timely trauma centre access to the entire population. This is evident from the country-wide disparities described by Hameed $e t a l^{2}$ in their study of trauma care access within Canada. As PTCs are more specialised than ATCs, very few exist across Canada. As a result, there are even more disparities related to PTC access within this country. 


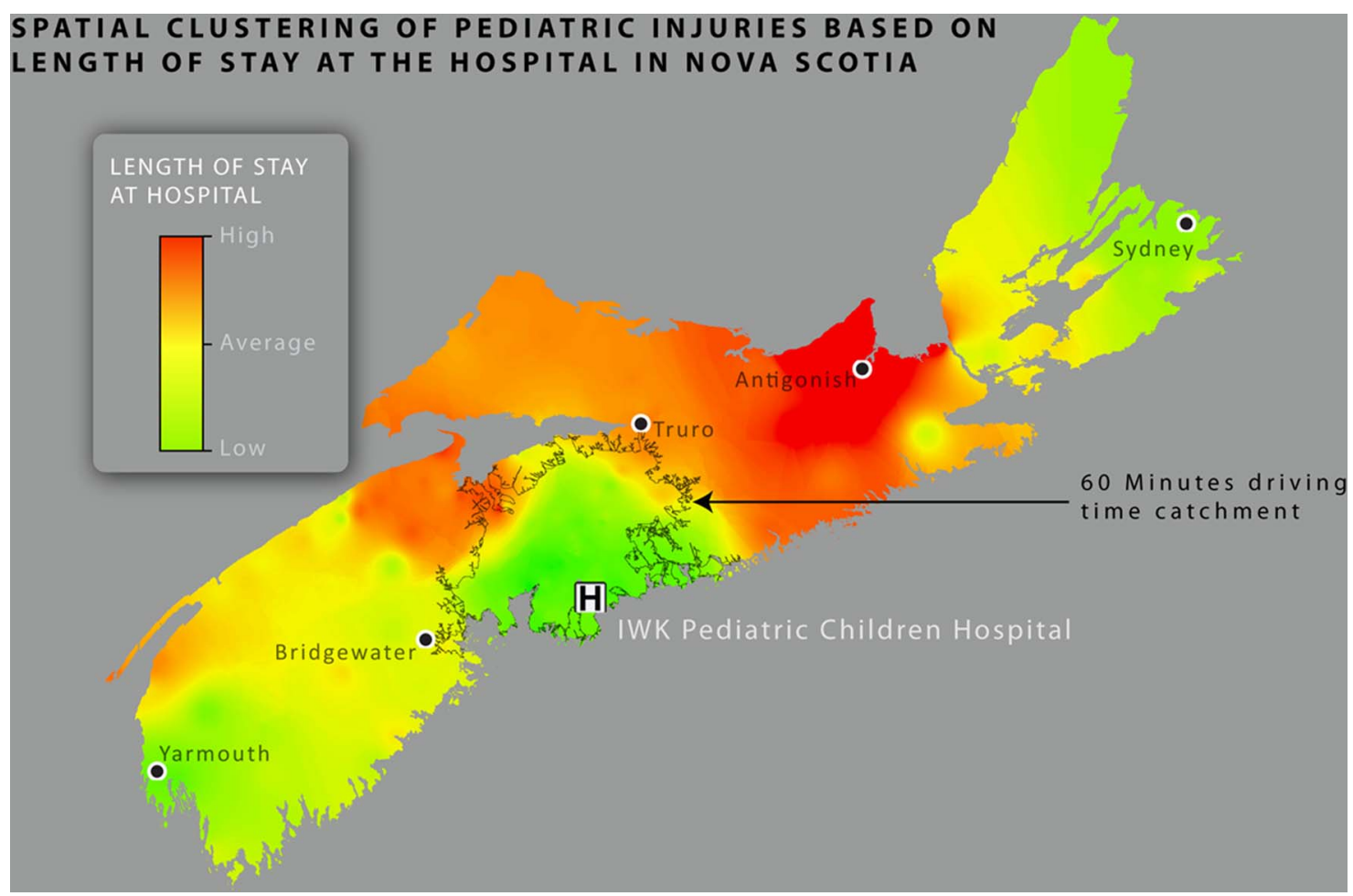

Figure 1 Length of hospital stays for paediatric trauma patients in Nova Scotia. A clustering of injuries resulting in relatively short hospital stays can be seen within the 60 min driving time catchment for IWK Children's Hospital.

In order to address timely access to care, regional trauma systems are established such that level 1 and 2 trauma centres rely on smaller non-trauma hospitals to provide intermediate care. ${ }^{23}$ The use of non-trauma hospitals for the provision of intermediate care prior to transfer to a trauma centre is essential to the care of severely injured patients geographically distant from a trauma centre. This is especially the case in large geographical areas where populations are widely dispersed. For example, when comparing BC with NS, we see a much higher percentage of BC's paediatric population within 60 min (54-47\%, respectively) of a PTC. On the contrary, the population outside the $60 \mathrm{~min}$ catchment resides in a vastly larger geographical area. Access to a PTC within these remote areas is also complicated by

Table 1 Average and median length of stay at the hospital increase as the injury is more severe

\begin{tabular}{|c|c|c|c|c|}
\hline \multirow[b]{2}{*}{$\begin{array}{l}\text { ISS } \\
\text { group }\end{array}$} & \multicolumn{2}{|c|}{$\begin{array}{l}\text { Average length of } \\
\text { stay at hospital } \\
\text { (days) }\end{array}$} & \multicolumn{2}{|c|}{$\begin{array}{l}\text { Median length of stay } \\
\text { at hospital (days) }\end{array}$} \\
\hline & $\begin{array}{l}\text { Inside } \\
60 \text { min }\end{array}$ & $\begin{array}{l}\text { Outside } \\
60 \mathrm{~min}\end{array}$ & $\begin{array}{l}\text { Inside } \\
60 \text { min }\end{array}$ & $\begin{array}{l}\text { Outside } \\
60 \mathrm{~min}\end{array}$ \\
\hline 12_15 & 5.1 & 6.3 & 4 & 6 \\
\hline 16_24 & 5.6 & 11.7 & 3 & 6 \\
\hline 25_75 & 15.5 & 21.9 & 8 & 12.5 \\
\hline 12_75 & 8.8 & 14.6 & 4 & 7 \\
\hline
\end{tabular}

the presence of island communities. In remote situations like this, smaller hospitals can play a pivotal role in providing access to care. In addition, the result of driving time versus length of stay at the hospital for BC clearly shows that this is the case. In BC, of the injuries occurring outside $60 \mathrm{~min}, 82 \%$ were first admitted to a non-PTC, while in NS this figure stands at only $14 \%$. However, the literature is almost always clear regarding where best to send patients if a choice is available, with the vast majorities of studies indicating that it is often worthwhile to obtain treatment directly from a PTC even when located further away. ${ }^{24} 25$ In order to improve patient care in remote areas, training some doctors to specialise in the treatment of severely injured paediatric patients can play a role in providing better care in earlier stages of treatment prior to arrival at the PTC. Furthermore, there is also a need to better understand in which situation it is better to directly transport patients to PTC, and when it is better to transport them to non-trauma hospitals first, taking into account factors such as type of injury, severity of injury and distance to care.

\section{Study limitations}

This study has a few limitations that need to be acknowledged. First, the location information for each injury recorded in the injury data sets is described by place of residence rather than place of injury. Unfortunately, place of injury data is not currently captured by hospitals when they receive patients. Although this issue is 
Figure 2 Variation in length of hospital stays for paediatric trauma patients in British Columbia. As demonstrated, there is no clear clustering of shorter hospital stays within the $60 \mathrm{~min}$ catchment for BC Children's Hospital. There is also no clear pattern across the province as a whole.

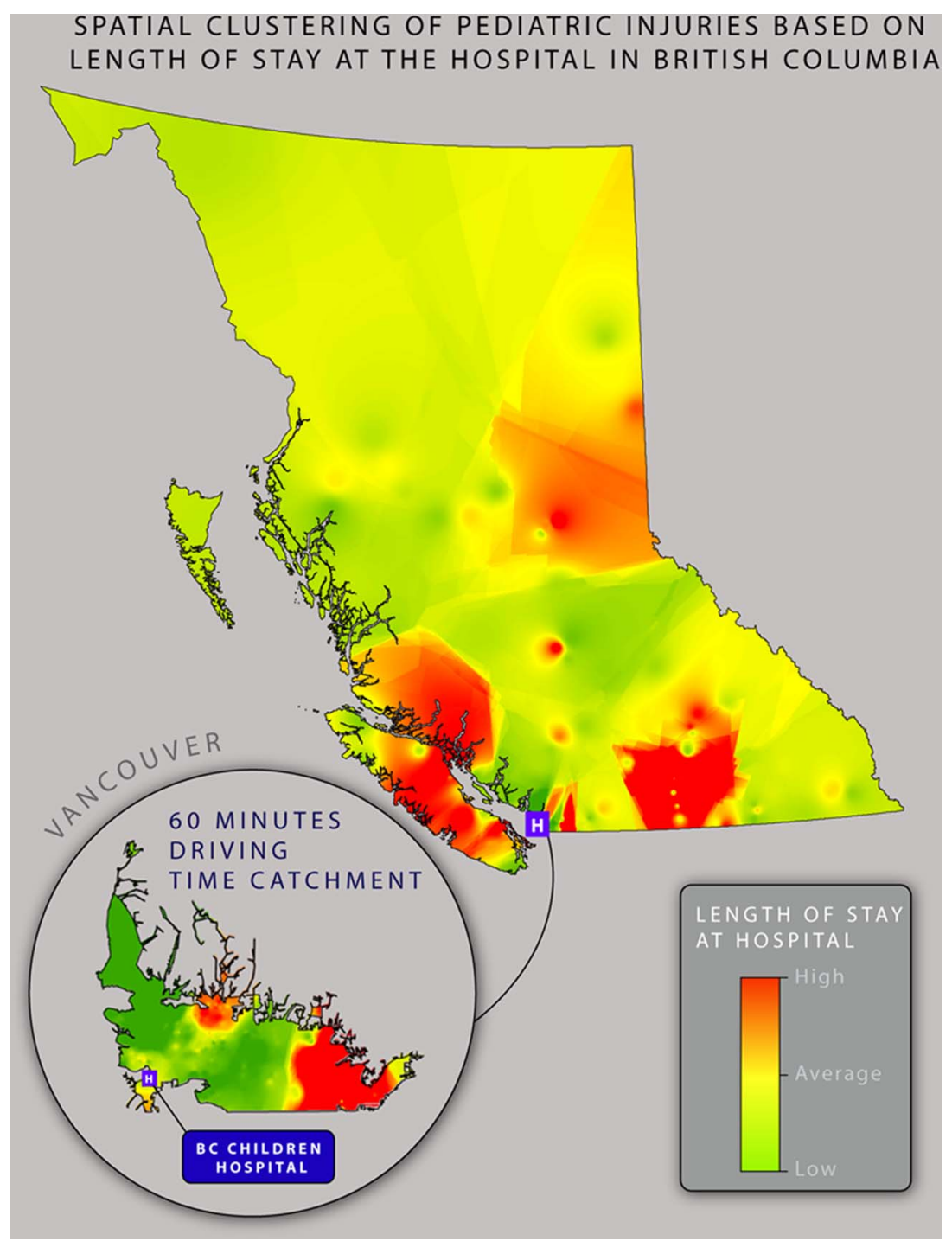

unavoidable, it may introduce some error within the driving time calculation. That said, most injuries do occur between 5 and 10 miles from home. ${ }^{20} 26$ Additionally, for the $\mathrm{BC}$ data set, information regarding the mode of transportation used to travel to the hospital was not provided. As this may provide some errors, only $7 \%$ of transports are done using fixed wing or helicopter. ${ }^{27}$ Additionally, most of those injuries will not affect this analysis as they can be easily identified as they will be transported directly to BC Children's Hospital from rural areas and islands which are not accessible by roads. Another limitation is the use of length of hospital stay as a proxy for injury outcome as it is not a patientfocused outcome. Other reasons may impact length of

Table 2 Average and median length of stay at the hospital both increase as the injury is more severe

\begin{tabular}{|c|c|c|c|c|c|}
\hline \multirow[b]{2}{*}{ ISS group } & \multicolumn{2}{|c|}{ Mean length of stay at hospital (days) } & \multicolumn{2}{|c|}{$\begin{array}{l}\text { Median length of stay at hospital } \\
\text { (days) }\end{array}$} & \multirow[b]{2}{*}{$\mathbf{n}$} \\
\hline & Inside $60 \mathrm{~min}$ & Outside $60 \mathrm{~min}$ & Inside $60 \mathrm{~min}$ & Outside $60 \mathrm{~min}$ & \\
\hline 12_15 & 3 & 14 & 3 & 7 & 45 \\
\hline 16_24 & 5 & 6.5 & 3 & 4 & 333 \\
\hline $25 \_75$ & 10 & 10.5 & 5 & 6 & 304 \\
\hline $12 \_75$ & 7 & 8.8 & 3 & 5 & 682 \\
\hline
\end{tabular}

The low number of patients with moderate injuries (12 15) indicates that most of the injuries arriving at BC Children's Hospital outside 60 min are probably those injuries that require specialised care that can only be provided by BC Children's hospital. Those also represent the injuries that have higher than average stay at the hospital.

ISS, Injury Severity Scale. 


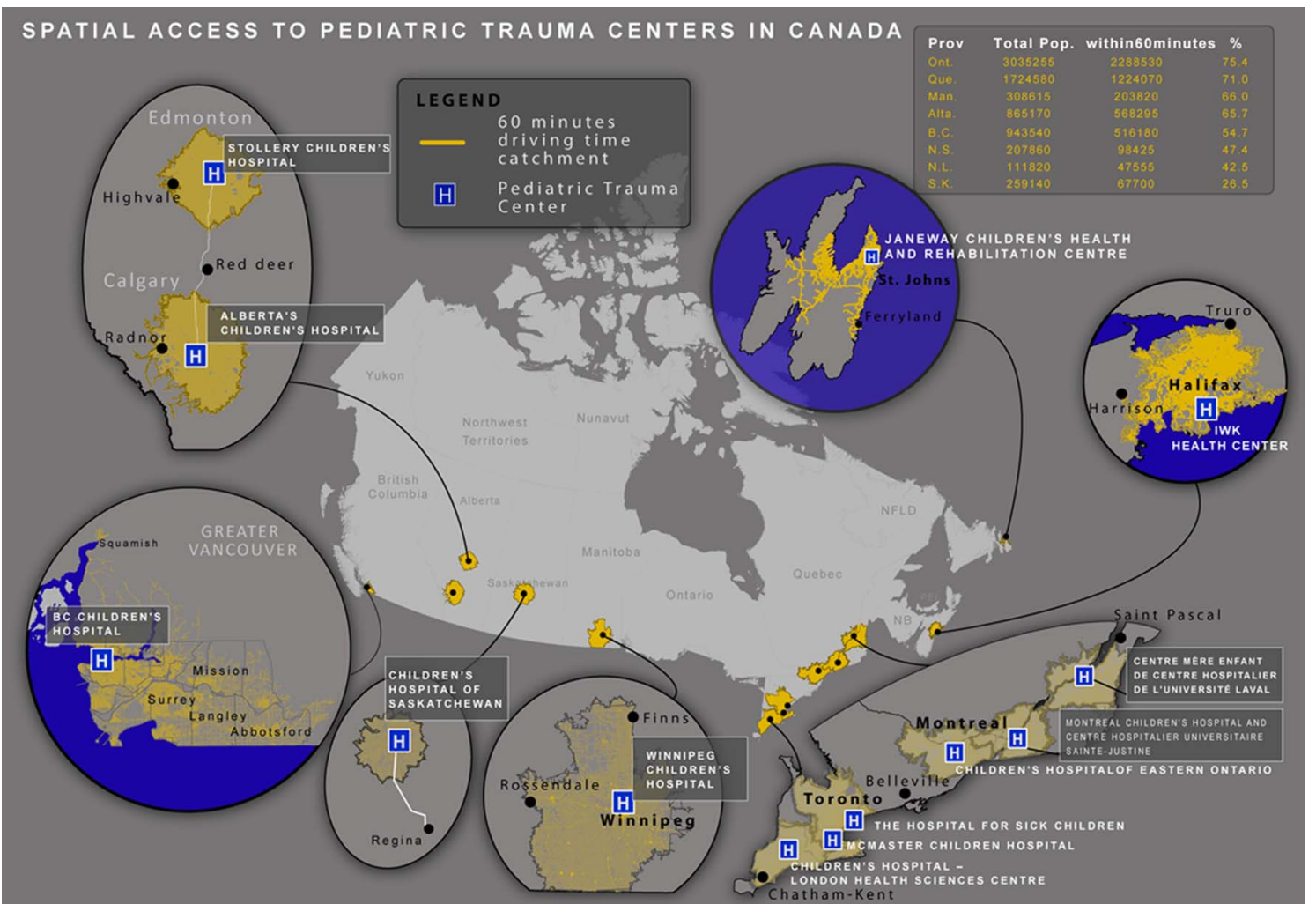

Figure 3 A 60 min driving time catchment around paediatric trauma centres (PTCs) across Canada, and the proportion of children aged $0-19$ years within $1 \mathrm{~h}$ of a PTC.

stay, for example, some patients may be kept in the hospital an extra day as a precaution just because they reside in remote areas. However, because of the acute shortage of beds in hospitals across Canada, we believe keeping patients an extra day is not a common practice. Measuring injury outcomes can be a difficult and complex process in that it often requires patient interviews and/or follow-up over a lengthy period of time in order to record elements such as visits to health facilities, duration of rehabilitation, and the ability to function in society. ${ }^{28}{ }^{29}$ For this reason, length of hospital stay has been used by other researchers as a measure of outcome. ${ }^{730}$ Other studies have also shown that length of stay at the hospital is directly correlated with injury severity and patient functionality. ${ }^{31}{ }^{32}$ Given the relatively large data set used in this study, and the lengthy period of time (9 years) over which it was collected, it was not feasible to collect this type of information. That said, we believe that length of hospital stay provided an appropriate measure of outcomes within the scope of this research. However, it is important to note that even though the differences in LOS at hospitals within $1 \mathrm{~h}$ and over $1 \mathrm{~h}$ from the PTC were statistically significant, they should not be interpreted as clinically significant. Finally, the driving time calculation does not incorporate traffic information. Therefore, the calculation underestimates driving time within urban areas, especially during times of heavy traffic congestion. However, this error will be consistent across all heavily populated areas, which is where PTCs are typically found.

\section{CONCLUSION}

The objectives of this study are to provide an overview of spatial access to PTCs across Canada, and to get a general overview of how distance to a PTC may affect outcome (depicted as length of stay at the hospital). The results clearly highlight differences in length of stay at the hospital as a result of spatial access to PTCs. However, the question of whether outcomes are better for those with injuries occurring outside the $1 \mathrm{~h}$ catchment of a PTC is something that needs to be investigated in future studies. Other considerations such as type of injury, age and gender may also affect injury outcome.

\section{Author affiliations}

${ }^{1}$ Department of Geography, Simon Fraser University, Burnaby, British Columbia, Canada

${ }^{2}$ Department of Pediatrics, Faculty of Medicine, University of British Columbia, Vancouver, British Columbia, Canada

${ }^{3} \mathrm{BC}$ Injury Research and Prevention Unit, Child and Family Research Institute, BC Children's Hospital, Vancouver, British Columbia, Canada

${ }^{4}$ Faculty of Health Sciences, Ben-Gurion University, Israel

${ }^{5}$ Department of Surgery, Dalhousie University, Halifax, Nova Scotia, Canada

Acknowledgements The authors would like to also acknowledge Population Data BC for their support and assistance in the data acquisition. 
Contributors OA and NS designed the study, conducted the analyses and drafted the manuscript. NLY helped revise the manuscript and made substantial contributions to the conception and design of the study. IP contributed substantially to conception of the study and helped revise the manuscript. MF assisted in the statistical analysis.

Funding OA was supported by the Canadian Institutes of Health Research.

Competing interests None declared.

Ethics approval Office of research Ethics-Simon Fraser University.

Provenance and peer review Not commissioned; externally peer reviewed.

Data sharing statement No additional data are available.

Open Access This is an Open Access article distributed in accordance with the Creative Commons Attribution Non Commercial (CC BY-NC 4.0) license, which permits others to distribute, remix, adapt, build upon this work noncommercially, and license their derivative works on different terms, provided the original work is properly cited and the use is non-commercial. See: http:// creativecommons.org/licenses/by-nc/4.0/

\section{REFERENCES}

1. SafeKidsCanada. Child and Youth Unintentional Injury: 10 years in review 1994-2003. Safe Kids Canada, 2006. www.mhp.gov.on.ca/ en/prevention/injury-prevention/skc injuries.pdf

2. Hameed SM, Schuurman N, Razek T, et al., Research Committee of the Trauma Association of Canada. Access to trauma systems in Canada. J Trauma 2010;69:1350-61; discussion 1361.

3. Petrosyan M, Guner YS, Emami CN, et al. Disparities in the delivery of pediatric trauma care. J Trauma 2009;67:S114-19.

4. Junkins EP Jr, O'Connell KJ, Mann NC. Pediatric trauma systems in the United States: do they make a difference? Clin Pediatr Emerg Med 2006;7:76-81.

5. Potoka DA, Schall LC, Ford HR. Improved functional outcome for severely injured children treated at pediatric trauma centers. J Trauma Acute Care Surg 2001;51:824-34.

6. Potoka DA, Schall LC, Gardner MJ, et al. Impact of pediatric trauma centers on mortality in a statewide system. J Trauma Acute Care Surg 2000;49:237-45.

7. Densmore JC, Lim HJ, Oldham KT, et al. Outcomes and delivery of care in pediatric injury. J Pediatr Surg 2006;41:92-8.

8. Canada TAo. Accreditation Guidelines. Secondary Accreditation Guidelines, 2011. http://www.traumacanada.ca/accreditation committee/Accreditation Guidelines 2011.pdf

9. Branas CC, MacKenzie EJ, Williams JC, et al. Access to trauma centers in the United States. JAMA 2005;293:2626-33.

10. Discharge Abstract Database (Hospital Separations). V2. In: Health BCMo, ed. 2011. Population Data BC: Population Data BC, 2011.

11. Consolidation File (MSP Registration \& Premium Billing). V2. In: Health BCMo, ed. Data Extract MOH (2011): Population Data BC, 2011.

12. Simons R, Kasic S, Kirkpatrick A, et al. Relative importance of designation and accreditation of trauma centers during evolution of a regional trauma system. J Trauma 2002;52:827-34.

13. Evans $\mathrm{C}$, Tallon J, Bridge $\mathrm{J}$, et al. An inventory of Canadian trauma systems: opportunities for improving access to trauma care. CJEM 2014;16:207-13.
14. Canada TAo. Trauma Association of Canada-Pediatrics. Secondary Trauma Association of Canada - Pediatrics. 2012. http:// www.traumacanada.org/page-983079

15. Canada C. Census of Canada. Secondary Census of Canada, 2006 http://www12.statcan.gc.ca/census-recensement/index-eng.cfm

16. GeoPinpoint, v2011.1. http://hdl.handle.net/11272/10264 DMTI Spatial, Inc. V1.

17. Cinnamon J, Schuurman N, Crooks V. A method to determine spatial access to specialized palliative care services using GIS BMC Health Ser Res 2008;8:140.

18. Schuurman N, Crooks VA, Amram O. A protocol for determining differences in consistency and depth of palliative care service provision across community sites. Health Soc Care Community 2010;18:537-48.

19. Nakayama DK, Copes WS, Sacco W. Differences in trauma care among pediatric and nonpediatric trauma centers. J Pediatr Surg 1992;27:427-31.

20. Palmer $\mathrm{C}$, Jones $\mathrm{K}$, Jones $\mathrm{P}$, et al. Urban legend versus rural reality: patients' experience of attendance at accident and emergency departments in west Wales. Emerg Med $J$ 2005;22:165-70.

21. Ehrlich $\mathrm{P}$, Ortega J, Mucha P. The need for a statewide pediatric trauma program. WV Med J 2001;98:66-9.

22. Sampalis JS, Denis R, Frechette $\mathrm{P}$, et al. Direct transport to tertiary trauma centers versus transfer from lower level facilities: impact on mortality and morbidity among patients with major trauma. J Trauma 1997;43:288-96.

23. Utter GH, Maier RV, Rivara FP, et al. Inclusive trauma systems: do they improve triage or outcomes of the severely injured? J Trauma 2006;60:529-37.

24. Nirula R, Maier R, Moore E, et al. Scoop and Run to the Trauma Center or Stay and Play at the Local Hospital: Hospital Transfer's Effect on Mortality. J Trauma 2010;69:595-9.

25. Wang NE, Chan J, Mahlow $\mathrm{P}$, et al. Trauma center utilization for children in California 1998-2004: trends and areas for further analysis. Acad Emerg Med 2007;14:309-15.

26. Boyle JM, Lampkin C, Schulman R, et al. Motor Vehicle Occupant Safety Survey: Crash Injury and Emergency Medical Services Report. US Department of Transportation, NHTSA, 2007.

27. Schuurman N, Bell N, Hameed MS, et al. A model for identifying and ranking need for trauma service in nonmetropolitan regions based on injury risk and access to services. J Trauma 2008;65:54-62.

28. Brooks N. The effectiveness of post-acute rehabilitation. Brain Injury 1991:5:103-9.

29. Stilwell P, Stilwell J, Hawley C, et al. Measuring outcome in community-based rehabilitation services for people who have suffered traumatic brain injury: the Community Outcome Scale. Clin Rehabil 1998;12:521-31.

30. Clague JE, Craddock E, Andrew G, et al. Predictors of outcome following hip fracture. Admission time predicts length of stay and in-hospital mortality. Injury 2002;33:1-6.

31. Lehmkuhl DI, Hall KM, Mann N, et al. Factors that influence costs and length of stay of persons with traumatic brain injury in acute care and inpatient rehabilitation. J Head Trauma Rehabil 1993;8:88-100.

32. Newgard CD, Fleischman R, Choo E, et al. Validation of length of hospital stay as a surrogate measure for injury severity and resource use among injury survivors. Acad Emerg Med 2010;17:142-50. 